\title{
A influência do fenômeno de expropriação sobre o desempenho de mercado das empresas brasileiras negociadas na $\mathrm{B3}$
}

\author{
Alberto Granzotto* \\ Clailton Freitas** \\ IGOR BERNARDI SONZA***
}

\begin{abstract}
RESUMO
O presente trabalho visa compor um fator constituído por variáveis que caracterizam a expropriação de minoritários e utilizá-lo para identificar a influência da expropriação destes sobre o desempenho de mercado das empresas brasileiras de capital aberto negociadas no Brasil, Bolsa e Balcão (B3). Para isso foi construído um fator representativo da expropriação de acionistas minoritários por meio da Análise Fatorial estimado por meio de Componentes Principais. Posteriormente, foram aplicados modelos de painéis dinâmicos, estimados pelo Método dos Momentos Generalizados para verificar a referida influência. De uma maneira geral, identificou que as variáveis de propriedade e controle bem como o desvio acionário são as melhores proxies representar o fenômeno de expropriação. Por fim, identificou-se que o fator expropriação é negativamente relacionada com o desempenho de mercado, isto é, há uma relação inversa entre o fenômeno de expropriação de acionistas minoritários e o desempenho da empresa.
\end{abstract}

Palavras-chave: Expropriação. Estrutura de controle. Desempenho. Componentes principais.

\section{THE INFLUENCE OF THE EXPROPRIATION PHENOMENON ON THE MARKET PERFORMANCE OF THE BRAZILIAN COMPANIES TRADED IN B3}

\begin{abstract}
This paper aims to compose a factor that consists of variables that characterize the expropriation of minority interests and to use it to identify the influence of expropriation of these on the market performance of Brazilian publicly traded companies on B3. For this purpose, a representative factor was created for the expropriation of minority shareholders through the Factor Analysis estimated through Principal Components. Subsequently, dynamic panel models were applied, estimated by the Generalized Moments Method to verify the influence. In general, it has identified that the variables of ownership and control as well as the stock deviation are the best proxies represent the phenomenon of expropriation. Finally, it was identified that the expropriation factor is
\end{abstract}

\footnotetext{
* http://orcid.org/0000-0001-6973-385X. http://orcid.org/0000-0001-6973-385X. UFSM. betorg@ymail.com

** http://orcid.org/0000-0003-0754-3211. http://orcid.org/0000-0003-0754-3211. UFSM. lcv589@gmail.com

*** http://orcid.org/0000-0003-0754-3211. http://orcid.org/0000-0003-0754-3211. UFSM. igorsonza@gmail.com
} 
negatively related to the market performance, that is, there is an inverse relationship between the phenomenon of expropriation of minority shareholders and the performance of the company.

Keywords: Expropriation. Control structure. Performance. Main components.

\section{INTRODUÇÃO}

Para uma maior eficiência do mercado de controle corporativo, ou mesmo para melhores avaliações do desempenho da empresa, a compreensão sobre a estrutura de Governança Corporativa torna-se muito importante, seja pela intensificação de transações entre empresas e países, ou mesmo pela separação que esta proporciona em termos de investimento e controle no âmbito da firma, (ALVES, 2016). Ultimamente, tem sido intensificada a preocupação das empresas em relação às práticas de Governança Corporativa, devido ao reconhecimento no mercado de capitais de tal prática como de extrema importância.

Marciano (2015) ressalta que a falência e o envolvimento de empresas em escândalos contábeis comprovam a ganância e a imprudência de seus gestores ao tomarem decisões, como o de maquiar os balanços contábeis, a fim de garantir e assegurar vantagens sobre os investidores, muitas vezes, em momentos nos quais estas empresas enfrentavam dificuldades financeiras.

Assim, de uma maneira geral a governança corporativa surge com o intuito de minimizar, por meio de um conjunto de mecanismos internos e externos, os custos decorrentes do problema de agência que surge quando um ou mais indivíduos, denominados "principais", contratam outros indivíduos ou grupo de indivíduos, denominados "agentes", para realização de um serviço que prescinde da outorga de autoridade para tomada de decisão. Portanto, a governança corporativa é uma forma de se mitigar os conflitos de interesse gerados pela separação entre propriedade e gestão de uma empresa, sendo que o centro das discussões sobre governança corporativa sempre foram os conflitos de agência (PUNSUVO; BARROS; KAYO, 2007).

A referida separação é fato gerador dos conflitos de agência (agency problem), que originalmente foram discutidos por: Berle e Means (1932), Jensen e Meckling (1976) e, mais recentemente, por La Porta et al (1998, 1999), Sonza e Kloeckner (2014), Schmidt e Fahlenbrach (2017), entre outros.

Nesse sentido há diversos conflitos, podendo ser entre executivos e acionistas, entre acionistas majoritários e minoritários e ainda entre portadores de título e acionistas (BERK; DEMARZO, 2009). Conforme Rosetti e Andrade (2014), com a dispersão do capital não se mantêm a sobreposição inicial da propriedade e da gestão, ou seja, os acionistas dispersos outorgam aos executivos não proprietários a gestão da firma, confiando, assim, que os outorgados cuidem tão bem de seus interesses quanto eles próprios o fariam. Entretanto, na prática há inúmeros desvios de conduta, antecipados pela literatura econômica e comprovado pela atenta observação da realidade corporativa.

No entanto, no mercado brasileiro o conflito entre executivos e proprietários é secundário, pois dado a base legal em civil law e aos fatores que diferenciam os modelos de 
governança corporativa ao redor no mundo, o conflito entre os proprietários majoritários e minoritários toma maiores proporções, como referenciado por La Porta et al (1999), Berk e Demarzo (2009), Morck et al (1988), Claessens (2002).

O modelo de governança brasileiro é o latino-americano, que diferentemente do modelo anglo-saxão (EUA, Reino Unido, entre outros), possui como principais características: governança corporativa embrionária, dada sua origem legal no Direito Civil; fraca proteção legal a minoritários; concentração proprietária (direito de voto mais direito de caixa); concentração de controle (direito de voto); baixa quantidade de ações negociadas com direito de voto; ocorrências de estruturas piramidais entre outros. Por causa dessas características do modelo de governança brasileiro, a probabilidade de expropriação aumenta, levando o conflito de agência, entre acionistas majoritários e minoritários, a tomarem maiores proporções (BERK; DEMARZO, 2009; ROSETTI; ANDRADE, 2014).

Como supracitado a governança corporativa se vale de mecanismo para mitigar os problemas entre os agentes. Um dos seus principais mecanismos é a estrutura de propriedade, isto é, a forma em que é distribuído o capital da empresa relativo aos votos e ao grau de concentração dos proprietários do capital (SONZA; KLOECKNER, 2014).

Em princípio, a concentração acionária traria benefícios para as organizações, visto que aumentaria a eficácia do monitoramento aos executivos (JENSEN; MECKING, 1976). Esse aumento da eficácia decorre do efeito alinhamento, ou seja, com a concentração acionária haveria uma melhora no desempenho das empresas, pela diminuição nos custos de agência (JENSEN; MECKLING, 1976). Contudo, La Porta et al. $(1998,1999)$ e Claessens et al. (2002) introduzem o efeito da proteção legal sobre os acionistas minoritários da empresa e demonstram que essa lógica pode ser invertida. Os referidos autores apresentaram evidências de que essa influência pode ser negativa, estando condicionada a base legal de cada país. Em outras palavras, na ausência de regulamentações adequadas que protegem os minoritários, o efeito alinhamento pode tornar-se o efeito expropriatório, isto é, a concentração acionária como viabilizador da centralização das tomadas de decisões, culminando muitas vezes em ações que prejudicam os minoritários.

A influência da estrutura de propriedade/controle vem sendo abordada em alguns trabalhos como os de Claessens et al. (2002), Sonza e Kloekner (2014), Sonza e Granzotto (2018). A marca comum nesses estudos é a evidência de que a concentração do controle exerce influência negativa sobre a performance das empresas. Assim, o conflito de agência entre majoritário e minoritário tem seu problema fundamental em operações financeiras em que os grandes investidores ao exercerem seus direitos em prol dos seus próprios interesses, colidem com os interesses de outros investidores minoritários. Isso acontece porque os investidores externos enfrentam riscos de que os retornos de seus investimentos possam nunca se materializar pela possibilidade de os acionistas majoritários expropriá-los (BAÍA; MARTELENC, 2010).

Nesse sentido, pode-se dizer que a expropriação é um problema de agência intimamente ligada a concentração de direitos de voto nas mãos de poucos acionistas, levando-os a auferir benefícios privados do controle, não os estendendo aos minoritários (SHLEIFER 
e VISHNY, 1997; LA PORTAet al., 1999; MORCK et al., 1988; CARVALHAL DA SILVA E LEAL, 2012). Portanto, é esperado que quanto maior concentração de controle maior a probabilidade de expropriação (LANZANA, 2004).

Ao relacionar estrutura de controle com desempenho corporativo, a grande maioria dos estudos verifica uma relação negativa com o desempenho, dado a alta chance de expropriação de direitos dos minoritários. Porém, essa constatação leva ao seguinte questionamento: existem outras variáveis que explicam a expropriação de minoritários? Há na literatura poucas tentativas de mensurar o potencial de expropriação das empresas por meio de seus componentes, pelo fato de ser difícil mensurá-la diretamente (EHRHARDT; NOWAK, 2001). Para viabilizar estudos nessa linha, geralmente, se utilizam proxys com base em mecanismo de governança corporativa, como o conselho de administração e a estrutura de propriedade e/ou controle, contudo estas captam efeito indireto.

Esforços se justificam no sentido de se construir uma medida de expropriação que possibilita mitigar problemas de endogeneidade entre estrutura de controle e desempenho, dado que uma estrutura acionária mais concentrada pode aumentar o desempenho, resultante do efeito alinhamento (em países com forte proteção legal, por exemplo) ou pode diminuí-lo, caso se expropriem os acionistas minoritários, e isso pode atrair/afastar novos investidores. Os estudos de Silveira (2004), Lameira e Ness (2011), Silva e Leal (2005) e Correia et al. (2011) buscaram o desenvolvimento de um índice para cálculo do nível de governança baseados nos pilares de acesso e conteúdo das informações, estrutura do conselho de administração, estrutura de propriedade e controle, porém estes índices não refletem a probabilidade de expropriação diretamente.

Para a efetivação do presente estudo constituiu-se uma amostra com oitenta empresas brasileiras de capital aberto com ações ordinárias e preferenciais negociadas a B3, sendo as informações coletadas de 2010 à 2018. Nesses dados fez-se, inicialmente, uma análise estatística descritiva e análise de correlação, após, foi construído um fator representativo da expropriação de acionistas minoritários por meio da Análise Fatorial (AF) estimado por meio de Componentes Principais (ACP). Posteriormente, foram aplicados modelos de painéis dinâmicos, estimados pelo Método dos Momentos Generalizados (GMM) para verificar a referida influência.

Portanto, o presente artigo busca responder a seguinte problematização: quais variáveis têm o potencial de representar o fenômeno de expropriação? A literatura ao utilizar proxies de propriedade e controle unicamente da concentração acionária omite alguma variável ao caracterizar a expropriação com o desempenho?

Nesse sentido, o presente trabalho visa compor um fator constituído por variáveis que caracterizam a expropriação de minoritários e utilizá-lo para identificar a influência da expropriação de acionistas minoritários sobre o desempenho de mercado das empresas brasileiras de capital aberto negociadas no Brasil, Bolsa e Balcão (B3).

O presente artigo está subdividido em V sessões incluindo esta introdução. A sessão II apresenta a revisão de literatura, a sessão III evidencia os procedimentos metodológicos, a sessão IV apresenta os resultados do estudo e, por fim, a sessão V traz as conclusões e considerações finais. 


\section{FATORES EXPROPRIATÓRIOS E DESEMPENHO}

Qualquer debate sobre Governança Corporativa, seja no âmbito do sistema de controle, das regulamentações ou incentivos, está sempre calcado em uma história de conflitos de interesse e tentativas de minimizá-los. Todos esses conflitos têm importantes repercussões organizacionais sobre a governança corporativa, a estrutura, a eficiência organizacional e os sistemas de remuneração (SHLEIFER; VISHNY, 1997).

A natureza e a magnitude destes conflitos, bem como os principais mecanismos de correção dependem das características legais de cada país. Shleifer e Vishny (1997) apontam que grande parte da diferença nos sistemas de governança corporativa em todo o mundo advém das diferenças na natureza das obrigações legais que os gerentes têm com os financiadores, bem como nas diferenças em como os tribunais interpretam e impõem essas obrigações.

De uma maneira geral, as relações de agência ocorrem quando o principal delega autoridade ao agente e o bem-estar do primeiro é afetado pelas escolhas do segundo, isto é, os interesses do principal e do agente são divergentes (JENSEN; MECKLING, 1976). Os conflitos de agência, seja entre executivos e acionistas ou entre acionistas (majoritários e minoritários), é uma questão amplamente difundida na academia já documentada por Berle e Means (1932), Jensen e Meckling (1976), Shleifer e Vishny (1997) e La Porta et al (1998, 1999), conforme ressaltada na seção. Sob uma concepção teórica mais ampla, esses estudos trazem à tona a divergência de interesses das relações intrafirma dos diversos atores envolvidos sobre o gerenciamento.

Segundo Rosetti e Andrade (2014) os conflitos e os custos de agência são derivações diretas da separação da propriedade do controle bem como de uma das características do moderno mundo corporativo que é a dispersão do capital de controle, tanto a resultante do financiamento das firmas por emissões e Oferta Públicas (IPOs), quanto a que decorre do inexorável processo de partilha da propriedade pela sucessão dos acionistas fundadores, geração após geração

Nesse sentido, Shleifer e Vishny (1997) apontam que as dificuldades dos investidores quanto à segurança de seus rendimentos emergem da separação entre a gestão e o investimento nas empresas e, consequentemente, do risco de seus recursos serem expropriados ou mesmo investidos em projetos não atrativos. Segundo La Porta et. al. (1998), estas dificuldades são melhores contornadas pelo grau de proteção ao investidor, no qual é amplamente determinado pela origem legal do país, especificamente se seu sistema legal se baseia na commom law britânica (mais proteção) ou na civil law francesa, alemã ou escandinava (menos proteção).

Nos Estados Unidos, os conflitos de agência decorrentes da referida separação resultam em ações para monitorar os gestores e bloquear as práticas de gestão que estejam divergentes dos objetivos dos acionistas. Assim, a proteção aos investidores nos EUA é geralmente vista como estando entre as melhores do mundo, pelo grau no qual os investidores são protegidos contra a expropriação de fundos (BERK; DEMARZO, 2009). Diferentemente dos EUA, o cenário brasileiro é considerado precário em termos de sistema de governança corporativa, pois dado sua base legal na Civil Law, os acionistas não possuem mecanismos fortes de proteção, culminando em expropriação de acionistas minoritários. 
O conflito de agência mais discutido pela literatura é o clássico conflito entre controladores (principal) e administradores (agentes). Contudo, no mercado brasileiro o conflito entre majoritários (agente) e minoritários (principal) toma maiores proporções como referenciado por La Porta et al (1999), Morck et al (1988), Claessens (2002). Como Sonza e Kloeckner (2014) apontam, esses conflitos podem ser mais bem examinados por meio da estrutura de propriedade e controle, pois o mais importante direito legal dos acionistas é o direito de votar em assuntos corporativos importantes, (SHLEIFER; VISHNY, 1997). A princípio a concentração acionária estaria relacionada a benefícios para as organizações, visto que aumenta a eficácia do monitoramento aos executivos (JENSEN; MECKING, 1976).

De acordo com Jensen e Meckling (1976), a estrutura proprietária mais concentrada pode mitigar os problemas de agência, proporcionando mecanismos de monitoramento mais eficientes, pois quanto maior a concentração dos acionistas, maior o incentivo para estes monitorarem a empresa com menor custo agregado. Da mesma maneira, Shleifer e Vishny (1986) apontam que a maneira mais direta de alinhar o fluxo de caixa e controlar os direitos de investidores externos é concentrar as participações acionárias, já que através desta os acionistas têm controle de voto suficiente para pressionar a administração em alguns casos, ou talvez até para expulsar a administração por meio de uma briga por procuração (proxy fight) ou uma aquisição hostil (takeover).

Contudo, como supracitado, o cenário brasileiro carece de medidas eficientes de proteção aos minoritários, fazendo com que essa influência seja modificada. Assim, na ausência de regulamentações adequadas que protegem os minoritários, a estrutura acionária como mecanismo de monitoramento aos gestores pode tornar-se um mecanismo de entrincheiramento, como já argumentado, isto é, a concentração acionária como viabilizador da centralização das tomadas de decisões, culminando muitas vezes em expropriação de minoritários.

Nesse contexto, Silveira (2004) argumentou que, no Brasil, os acionistas que detêm maior parte do controle tendem a utilizar o capital e o poder em prol dos seus interesses, indo contra às expectativas dos minoritários. Esta questão fica evidente no trabalho de Sonza e Kloeckner (2014), os quais indicaram que a alta concentração de controle pode prejudicar o desempenho das empresas brasileiras, devido a expropriação.

La Porta et al. (1998) argumentaram que, na ausência de proteção adequada das minorias, investidores se protegem exercendo controle direto por meio de grandes blocos de ações. A concentração de controle pode afetar negativamente o desempenho das empresas, pois funcionam como um mecanismo de expropriação do fluxo de caixa (SILVEIRA, 2004; SONZA e KLOECKNER, 2014). Portanto, uma maior concentração de controle impactaria numa maior probabilidade de expropriação (LANZANA, 2004). Além da estrutura de controle, outras questões também caracterizam o processo expropriatório.

Conforme Shleifer e Vishny (1997) e La Porta et al. (1999), a obtenção de benefícios privado e as divergências de interesses entre majoritários e minoritários são ainda maiores nos casos em que os direitos de controle são superiores aos direitos sobre os fluxos de caixa da empresa. Essa situação é observada quando há o desvio da regra "uma ação, um voto", mediante, por exemplo, emissão de ações sem direito a voto e, também, quando 
há estruturas piramidais. Neste caso, os grandes investidores têm, não apenas uma forte preferência, mas também a capacidade de não pagar fluxos de caixa como distribuições a todos os investidores, mas sim pagar apenas a si próprios, usando dividendos especiais ou explorando outras relações comerciais com as empresas.

Do ponto de vista da teoria da agência, Jensen e Meckling (1976) argumentam que os dividendos representam uma ferramenta para alinhar interesses entre acionistas e administradores, mitigando assim o conflito de agência, pois um alto pagamento de dividendos minimiza o fluxo de caixa livre que poderia ser investido em projetos subótimos de baixo risco ou projetos que buscam interesses pessoais de gestão.

Ao discutir o problema de agência entre controladores e minoritários, Faccio e Lang (2001) e apontam que a análise do pagamento de dividendos fornece evidências sobre a expropriação de minoritários, pois estes podem eliminar a riqueza corporativa do controle interno. Os autores trazem evidências que os dividendos podem ser uma forma de sinalizar que a empresa está em boas condições financeiras e que os acionistas minoritários não serão expropriados. Adicionalmente, ao examinar a relação do pagamento de dividendos com a proteção legal dos países, os autores evidenciam que dividendos mais altos são pagos por corporações em países com forte proteção legal de acionistas minoritários, como aqueles países com códigos baseados em Common Law e não em Civil Law (LA PORTA et al, 2000).

Recentemente, alguns estudos têm corroborado com estas hipóteses. Athari et al (2016) buscaram relacionar os níveis de proteção ao investidor nos países árabes e seus efeitos nas políticas de dividendos, no caso de firmas financeiras que operam sob baixos níveis de proteção ao investidor. Os autores apoiam o modelo de agência de substituição de dividendos, apresentado por La Porta et al. (2000), para os bancos islâmicos, pois, apontam que o pagamento de dividendos é usado como um mecanismo substituto para aliviar problemas de agência, relativamente mais pronunciados, em relação a expropriação de minoritários.

Da mesma forma, Rossi et al (2017) e LaRivieri et al (2018) buscaram testar as hipóteses de sinalização para a não expropriação (modelo substituto) bem como para a desapropriação de fundos corporativos (modelo de resultados). Os resultados dos autores corroboram com os resultados de La Porta et al. (2000) ao evidenciar que o pagamento dos dividendos é mais alto nos tratamentos de alta proteção do que nos correspondentes de baixa proteção aos acionistas minoritários.

A expropriação de acionistas minoritários pode ser visualizada, também, pela ótica de contratos. Um dos direitos mais importantes dos acionistas, se não o mais importante, é o direito de votar em assuntos corporativos importantes, como fusões e liquidações, bem como em eleições de conselhos de administração (SHLEIFER; VISHNY, 1997).

Nesse sentido, conforme aponta La Porta et al (1999) um dos mecanismos contratuais mais utilizados para aumentar o poder de controle dos acionistas é o acordo de acionistas. Este seria uma forma contratual que celebra a conciliação de interesses bem como o estabelecimento de normas de atuação dos acionistas (CARVALHAL DA SILVA, 
2012). Carvalhosa (2003) classifica os acordos em duas categorias: acordo de controle e voto e; acordo de ações (ou bloqueio).

$\mathrm{O}$ acordo de controle e voto acontece quando os acionistas de uma mesma companhia se unem com um objetivo em comum. Especificamente, o acordo de controle pressupõe a consecução, por meio da composição absoluta das ações com direito a voto, o controle da companhia. Conforme Gelman et. al. (2015), esses acordos servem para os acionistas buscarem o controle das decisões e gestão efetiva da empresa, isto é, o controle para compor os interesses de acionistas que ex ante não poderiam influir com supremacia. Os autores relatam que os acordos de controle podem levar a uma série de problemas de agência, dado a alta concentração de controle, sendo os motivos para isso, os mesmos apontados anteriormente. Assim, os acordos de acionistas podem acarretar em benefícios privados do controle em detrimento de minoritários, podendo afetar negativamente o desempenho das empresas.

Ainda em relação a primeira categoria, os acordos de voto, diferentemente dos acordos de controle, visam a abrangência de um percentual mínimo por parte dos minoritários (necessário para $10 \%$ em ações ON e $15 \%$ em ações PN), com o intuito de fiscalizar ou se opor aos controladores, visando dessa maneira aumentar a sua proteção (CARVALHOSA, 2003; DA SILVA et al., 2015). Esta modalidade de acordo, geralmente é apontado como benéfico para a empresa, pois mitigam as possibilidades de expropriação por parte dos controladores, levando a aumentos de desempenho.

Alternativamente, o acordo de ações tem seu objetivo na determinação do direito de preferência na venda para terceiros, ou transferência das ações entre os membros apenas com o consentimento das partes. Destaca-se que a prática do acordo de ações visa estipular não a venda de ações, contudo, a promessa de fazê-la mediante condições pré-determinadas (Carvalhosa, 2003). Pela Lei das SA's, promulgada em 2001, no qual buscou-se promover maior proteção aos acionistas minoritários, estabelecendo obrigatoriedade do adquirente do controle da companhia, em caso de alienação direta e indireta, assegurando aos acionistas minoritários preço equivalente a no mínimo $80 \%$ do valor pago pelas ações do bloco de controle. Esta cláusula é denominada tag along (SILVEIRA, 2004).

Esta é uma cláusula pré-determinada que neutraliza os efeitos de vendas ineficientes, impedindo qualquer acionista de vender a sua participação a terceiros, nos termos que lhe permitiriam pagar mais do que a sua parte do excedente que lhe é devido nos termos do acordo, ou seja, reduz o ganho total se uma das partes maximizar seu retorno individual em detrimento do outro. Portanto, o tag along visa beneficiar e proteger o minoritário frente ao comportamento oportunista do controlador. Adicionalmente, há também a possibilidade de ter cláusulas que beneficiem os controladores como o drag along, no qual determina que os acionistas minoritários têm o dever de alienar suas ações, caso o acionista majoritário decida vender sua parte (LACAVE; GUTIERREZ, 2010).

Ainda relacionado ao fenômeno de expropriação, alguns artigos apresentam que empresas que são auditadas por empesas reconhecidas no mercado desenvolvem políticas de divulgação eficientes tendem a ter um custo de capital mais baixo melhorando seu desempenho (DEPOERS, 2000). 
Como visto, a expropriação está relacionada a diversos fatores apontados pela literatura, como a concentração de controle, a presença de estruturas piramidais, ao pagamento de dividendos, os acordos de acionistas, as cláusulas contratuais, entre outros como operações de tunneling, benefícios de reputação, self-dealing. (EHRHARDT; NOWAK, 2001; SILVEIRA, 2004).

\section{METODOLOGIA}

Para verificar a influência da expropriação no valor de mercado o presente trabalho percorre as seguintes etapas:

\subsection{Fonte, base dos dados e amostra}

Os dados básicos relacionados ao Balanço Patrimonial e Demonstração de Resultados do Exercício, dentre outros, são extraídos do ECONOMÁTICA Já os dados sobre a expropriação são extraídos do site do Brasil, Bolsa e Balcão (B3) e dos Relatórios de Referências (RF). O software utilizado é o Stata SE 14®.A final constitui-se de 80 empresas que negociam ações na B3 durante o período de 2010 à 2018 devido a disponibilidade de dados.

\subsection{O modelo econométrico}

Inicialmente, conforme, Mingoti $(2005,2017)$, a análise fatorial tem como objetivo principal descrever a variabilidade original de um vetor de variáveis $X$, em termos de um número $k$ menor de variáveis aleatórias, denominadas fatores comuns (comunalidade mais erro) que estão relacionadas com o vetor original $X$ através de um modelo linear. A estimação dos fatores deu-se por meio da análise de componentes principais descrita a seguir.

A análise de componentes principais tem por propósito explicar a estrutura de variância e covariância de um vetor aleatório, composto de $p$-variáveis aleatórias, através da construção de combinações lineares das variáveis originais, sendo ortogonais entre si. Assim, as informações contidas nas $p$ variáveis originais são substituídas pelas informações contidas em $k$ componentes principais, onde $k<p$ (MINGOTI, 2017).

Assim, é investigado se todas as variáveis contribuíram para explicar a variabilidade total dos dados. Conforme Jhonson e Wichern (1998), a reprodução da variabilidade total do sistema requer as $p$ variáveis, porém, frequentemente a maior parte dessa variabilidade pode ser explicada por um número menor derivados em ordem decrescente de importância, isto é, o primeiro componente principal capta o máximo da variância possível, o segundo capta o máximo possível do restante e assim sucessivamente. Essas definições se dão pelos passos seguintes. Seja Seja $X^{\prime}=\left[\begin{array}{llll}X_{1} & X_{2} & X_{3} \ldots . . X_{p}\end{array}\right]$ um vetor de $p$ variáveis com matriz de variâncias e covariâncias $\Sigma$.

$$
\operatorname{Var}-\operatorname{Cov}(X)=\sum \operatorname{pxp}
$$

em que, os componentes principais são combinações lineares dos X's, isto é,

$$
Y_{i}=e_{p}^{\prime} x=e_{p 1} x_{1}+e_{p 2} x_{2}+\cdots+e_{p p} x_{p}
$$




$$
\operatorname{Max} \operatorname{Var}\left(Y_{i}\right)=e_{i}^{\prime} \Sigma e_{i}
$$

s. a

Assim,

$$
e_{i}^{\prime} e_{i}=1
$$

$e_{i}^{\prime} e_{k}=0$

onde a derivada parcial em relação a $e_{i}$ é dada por,

Ajeitando a equação,

$$
\frac{\partial L}{\partial e_{i}}=2 \Sigma e_{i}-2 \lambda e_{i}
$$

$$
L=e_{i}^{\prime} \sum e_{i}-\lambda\left(e_{i}^{\prime} e_{i}-1\right)
$$

$$
(\Sigma-\lambda \mathrm{I}) e_{i}=0
$$

Assim, o problema fundamental é encontrar as raízes características $\left(\lambda_{i}\right)$, em que por definição $\lambda_{1} \geq \lambda_{2} \geq \cdots . . \lambda_{p}, \Sigma$ é a matriz de variância e covariância dos X's. Por fim, os coeficientes dos componentes principais são os elementos dos vetores característicos $\left(e_{i}\right)$.

Após a estimação dos componentes principais, foram aplicados os seguintes testes com o intuito de aumentar a robustez do modelo:

(i) Teste de esfericidade de Bartlett (Teste $t$ ): este teste visa identificar se a matriz de correlações é estatisticamente igual a uma matriz identidade;

(ii) Rotação dos dados por meio do Método VARIMAX: com intuito de melhorar a interpretação dos dados por meio da estimação de uma nova matriz ortogonal;

(iii) Teste de Kaiser-Meyer-Olkin (KMO): visa, por meio da matriz de correlações inversa, verificar o ajustamento da análise fatorial aos dados, e,

(iv) Teste de Alpha de Crombach: verificar a consistência interna por meio da intercorrelação entre as variáveis.

Nesse contexto, a metodologia de componentes principais foi utilizada para verificar quais variáveis relacionadas a expropriação têm maior capacidade de explicação da variância total dos dados. Depois de verificada quais variáveis são utilizadas, forma-se um fator intitulado de "Fator Expropriatório" no qual foi usado como regressando na estimação por GMM.

O Método dos Momentos Generalizados (GMM) foi desenvolvido por Hansen (1982) e provê uma estrutura conveniente para a obtenção de estimadores assintoticamente eficiente. O GMM para dados em painel é uma ferramenta que considera uma dada amostra de indivíduos ao longo do tempo e possibilita observações múltiplas de cada indivíduo na mostra. Conforme Bond (2002) é altamente recomendável investigar as propriedades das séries temporais das séries individuais quando se usam estimadores GMM para modelos de 
painel dinâmico, isto é, considerado a variável dependente como independente do modelo e ainda defasada.

O uso do GMM é recomendado devido a alguns fatores como a possibilidade de dirimir o problema de endogeneidade, isto é, o efeito feedback. Este problema ocorre quando os valores passados da variável dependente influenciam os valores contemporâneos e/ou futuros das variáveis independentes. (BARROS et al., 2009) Esse problema é denominado por Wintoki, Linck e Netter (2008) como "endogeneidade dinâmica" dos estudos de finanças corporativas. Para os autores, esse problema pode ser mitigado pela inclusão de defasagens da variável explicada no modelo de regressão, como empregado pelo GMM.

Além de diminuir problemas de endogeneidade, o GMM, oferece uma estrutura mais eficiente na obtenção de estimadores pelo relaxamento das condições de homocedasticidade necessárias para aplicação do Métodos dos Mínimos Quadrados Ordinários (OLS). Esta condição tem relação com a dinamicidade do modelo como pode ser vista abaixo:

$$
y_{i t}=y_{i, t-1}+\mu_{i t} \text {, no qual, } u_{i t}=\alpha_{i}+v_{i t}
$$

Onde os termos de perturbação e têm ambos médias nulas se considerado que
a) $E\left(y_{i 0}\right)=0$
b) $E\left(y_{i 0} v_{i t}\right)=0, \ldots, t$;
c) $E\left(\alpha_{i 0} v_{i t}\right)=0, \ldots, t$;

Os termos de perturbação não estão correlacionados, para todo i.

Destas condições, podem-se retirar $T(T-1) / 2$ condições de momento (MÁTIAS, 1999; SONZA e KLOECKNER, 2012):

$$
\mathrm{E}\left(y_{i t} \mu_{i t}\right) \text { para } \mathrm{t}=2, \ldots, \mathrm{T} ; \mathrm{s}=0,1, \ldots, \mathrm{T}-2
$$

onde,

$$
\mu_{i t}=v_{i t}-v_{i, t-1}
$$

Esta última condição vem dos pressupostos de que os $v_{i t}$ não são correlacionados entre si, nem com os efeitos específicos, nem tão pouco com $y_{i 0}$, não necessitando respeitar, portanto a condição de homocedasticidade. Neste caso, como afirma Mátyás (1999), haverá ganhos de eficiência permitidos pelo relaxamento da condição de homocedasticidade, por possuir um pressuposto mais robusto.

No que tange o GMM, existem duas possibilidades desses estimadores serem trabalhados: o GMM-Dif (em diferenças), proposto por Arellano e Bond (1991), ou o GMM-Sys (Sistêmico) de Blundell e Bond (1998). Como argumentam Bond et al. (2002), esta última metodologia é capaz de superar possíveis problemas dos estimadores GMM em diferenças (GMM-dif), decorrentes de efeitos persistentes de séries temporais que acabam por inviabilizar as defasagens das variáveis como instrumentos apropriados para as variáveis endó- 
genas. Portanto, o GMM-Sys é escolhido, devido ao fato deste modelo aceitar um conjunto de instrumentos disponíveis e permitir estimativas mais precisas, apesar de as suposições sobre as condições iniciais serem mais restritivas. Conforme Bond (2002) o estimador GMM- Sys é considerado "estendido", isto é, tem menor viés de amostras finitas e maior precisão quando é necessário estimar parâmetros autorregressivos, usando séries com alta persistência. Em suma os parâmetros podem não ser identificados ao usar o GMM de primeiras diferenças quando as séries são passeios aleatórios (random walk) e, geralmente, a identificação pode ser fraca quando as séries são processos de quase raiz unitária.

Embora o GMM-Sys não suponha que as variáveis tenham distribuição normal e a heteroscedasticidade, a presença destas não inviabiliza sua aplicação, contudo para que os resultados dos modelos estimados pelo GMM-Sys sejam robustos, alguns pressupostos precisam ser atendidos. Assim, com o intuito de tornar a análise robusta, foram aplicados alguns testes no estudo, tais como:

(i) Teste Arellano e Bond (1991): um dos pressupostos da aplicação do GMM-Sys é a rejeição da hipótese nula de ausência de autocorrelação serial de ordem um e rejeição de presença de autocorrelação de ordem 2 .

(ii) Teste de correlação: visa por meio da matriz de correlação especificar altas relações entre as variáveis.

(iii) Teste Qui-quadrado $\left(\chi^{2}\right)$ : onde a hipótese nula indica que as frequências observadas não são diferentes das frequências esperadas, ou seja, não existe diferença entre as frequências dos grupos (contagens) dos grupos, portanto, não há associação entre os mesmos;

(iv) Teste de Hansen (1982): os instrumentos devem estar correlacionados com os valores contemporâneos das variáveis de cada respectiva equação, além de serem exógenos, ou seja, não podem estar correlacionados com os erros contemporâneos. (ARELLANO; BOVER, 1995; BLUNDELL; BOND, 1998);

(v) Teste de Fisher (1932): testa a presença de raiz unitária em cada painel, isto é, busca verificar se o painel utilizado é estacionário.

(vi) Teste de Westerlund (2007): verificar a presença de cointegração, isto é, de relações de longo prazo com uma dimensão séries temporais e uma dimensão transversal.

E, por existir outliers (anormalidades), as variáveis foram winsorizadas (supressão de outliers) a 1\%. A seguir é apresentada a equação (1) usada no estudo.

$$
Q_{i t}=\beta_{1}+\boldsymbol{\beta}_{2} \boldsymbol{F} \boldsymbol{E}_{i t}+\beta_{3} \operatorname{CONT}_{i t}+\sum_{i}^{n} \text { EFind }_{i}+\sum_{t}^{n} \text { EFtemp }_{t}+\varepsilon_{i t}
$$


Quadro 3 - Definição de variáveis

Variáveis - Índice de Expropriação de Minoritários

\begin{tabular}{|c|c|c|c|c|}
\hline Componentes & Descrição/Cálculo & Autores & Sinal $^{1}$ & Descrição \\
\hline $\begin{array}{l}\text { EC Estrutura de } \\
\text { controle/propriedade } \\
\text { Brasil } \\
\text { AP: Acionista prin- } \\
\text { cipal } \\
\text { TPA: Três principais } \\
\text { acionistas } \\
\text { CPA: Cinco princi- } \\
\text { pais acionistas }\end{array}$ & $\begin{array}{l}\text { Percentual de ações ordi- } \\
\text { nárias/total pertencentes ao } \\
\text { acionista principal e dos três } \\
\text { principais acionistas. }\end{array}$ & $\begin{array}{l}\text { La Porta et al. } \\
\text { (1999); Silveira } \\
\text { (2004); Sonza e } \\
\text { Kloeckner (2014), }\end{array}$ & + & $\begin{array}{l}\text { A fraca proteção legal em países com } \\
\text { leis civis, com no caso do Brasil, faz } \\
\text { com que a concentração de controle } \\
\text { aumente as chances de expropriação } \\
\text { de minoritários. }\end{array}$ \\
\hline $\begin{array}{l}\text { Div. - Pagamento de } \\
\text { dividendos }\end{array}$ & Div $=\frac{\text { Dividendo Pago }}{\text { Valor d ação }}$ & $\begin{array}{l}\text { Jensen e Meckling } \\
\text { (1976); La Porta } \text { et } \\
\text { al (2000); Faccio } \\
\text { (2001); Athari et al } \\
\text { (2016); Rossi et al } \\
\text { (2017) e LaRivieri } \\
\text { et al (2018) }\end{array}$ & - & $\begin{array}{l}\text { Os dividendos podem ser uma forma } \\
\text { de sinalizar que a empresa está em } \\
\text { boas condições financeiras e que os } \\
\text { acionistas minoritários não serão } \\
\text { expropriados, diminuindo conflitos de } \\
\text { interesses. Assim, quanto maior for o } \\
\text { índice de payout, menor o potencial de } \\
\text { expropriação, dado maiores chances } \\
\text { de distribuição igualitária. Ademais, } \\
\text { empresas localizadas em países com } \\
\text { maior proteção legal a acionistas } \\
\text { minoritários (baseadas em sistemas de } \\
\text { common law) pagam dividendos mais } \\
\text { elevados, em comparação com países } \\
\text { onde a proteção legal é fraca (sistemas } \\
\text { de direito civil) }\end{array}$ \\
\hline $\begin{array}{l}\text { ADR - Programa de } \\
\text { American Depositary } \\
\text { Receipts }\end{array}$ & $\begin{array}{l}\text { Dummy - } 1 \text { caso a empresa } \\
\text { possua um ADR e } 0 \text { caso } \\
\text { contrário }\end{array}$ & Stulz (1999) & - & $\begin{array}{l}\text { Empresas que possuem ADR se ade- } \\
\text { quam a padrões norte-americanos. } \\
\text { Essa influência pode ser estendida as } \\
\text { negociações no Brasil, isto é, indica } \\
\text { que atende a exigências e requisitos } \\
\text { adicionais, os quais implicariam em } \\
\text { maior credibilidade. }\end{array}$ \\
\hline Tag along & $\begin{array}{l}\text { Dummy - } 1 \text { caso a empresa } \\
\text { possua tag along superior a } \\
80 \% \text { e } 0 \text { caso seja } 80 \% \text {. }\end{array}$ & $\begin{array}{l}\text { Baía e Martelenc } \\
(2010) \text {, Lacave e } \\
\text { Gutiérrez (2010) }\end{array}$ & - & $\begin{array}{l}\text { Processo de alienação/venda de con- } \\
\text { trole acionário. Porém, caso haja um } \\
\text { gap temporal entre aa operação (alie- } \\
\text { nação do controle) e oferta pode-se } \\
\text { perder valor. A oferta pública para os } \\
\text { minoritários busca possibilitar iguais } \\
\text { ganhos dos controladores. }\end{array}$ \\
\hline Drag along & $\begin{array}{l}\text { Dummy - } 1 \text { caso a empresa } \\
\text { possua drag along e } 0 \text { caso } \\
\text { contrário }\end{array}$ & $\begin{array}{l}\text { Lacave e Gutiér- } \\
\text { rez (2010) }\end{array}$ & + & $\begin{array}{l}\text { Caso o acordo de acionistas possua } \\
\text { esta clausula, quando um acionista } \\
\text { (geralmente o majoritário) recebe uma } \\
\text { proposta de venda, este tem o direito } \\
\text { de exigir a venda dos demais, isto } \\
\text { é caracterizando um dever de saída } \\
\text { conjunta. }\end{array}$ \\
\hline
\end{tabular}

1 O respectivo sinal apresentado refere-se a relação da variável com a expropriação de minoritários. 


\begin{tabular}{|c|c|c|c|c|}
\hline $\begin{array}{l}\text { SEG. GOV. - Seg- } \\
\text { mento de Governança } \\
\text { Corporativa }\end{array}$ & $\begin{array}{l}\text { Novo mercado } \\
\text { Dummy - } 1 \text { caso a empresa } \\
\text { negocie ações no NM e } 0 \\
\text { caso contrário } \\
\text { Nível } 2 \\
\text { Dummy - } 1 \text { caso a empresa } \\
\text { negocie ações no Nível } 2 \text { e } 0 \\
\text { caso contrário } \\
\text { Nivel } 1 \\
\text { Dummy - } 1 \text { caso a empresa } \\
\text { negocie ações no Nível } 1 \text { e } 0 \\
\text { caso contrário }\end{array}$ & $\begin{array}{l}\text { Silveira (2004); } \\
\text { Lameira e Ness Jr. } \\
(2011)\end{array}$ & - & $\begin{array}{l}\text { As empresas negociadas em níveis } \\
\text { diferenciados de Governança Corpora- } \\
\text { tiva seguem diretrizes mais severas no } \\
\text { que tange a boas práticas. A negocia- } \\
\text { ção no Novo Mercado, por exemplo, } \\
\text { acontece mediante emissão de ações } \\
\text { ordinárias somente, o que eu diminui } \\
\text { a possibilidade de expropriação já } \\
\text { que não possuirá desvio acionário, ou } \\
\text { várias classes de ações. }\end{array}$ \\
\hline $\begin{array}{l}\text { Desvio Acionário } \\
\text { DESA: Desvio } \\
\text { acionário Acionistas } \\
\text { Principal } \\
\text { DEST: Desvio acio- } \\
\text { nário dos três acionis- } \\
\text { tas principais } \\
\text { DESC: desvio acio- } \\
\text { nário dos cinco acio- } \\
\text { nistas principais }\end{array}$ & $\begin{array}{l}\text { Diferença Percentual do } \\
\text { direito de ações com direito } \\
\text { a voto dos controladores } \\
\text { em relação ao direito de } \\
\text { propriedade (participação no } \\
\text { capital total da empresa) } \\
\text { Razão entre estrutura de } \\
\text { controle e estrutura de } \\
\text { propriedade (caso o valor } \\
\text { seja maior que 1, há desvio } \\
\text { acionário) }\end{array}$ & $\begin{array}{l}\text { Silveira (2004); } \\
\text { Carvalhal da Silva } \\
\text { e Leal (2012), } \\
\text { Shleifer e Vishny, } \\
\text { 1997; La Porta et } \\
\text { al (1999), Claes- } \\
\text { sens et al (2002), } \\
\text { Correia et al } \\
\text { (2011); }\end{array}$ & + & $\begin{array}{l}\text { As divergências de interesses entre } \\
\text { majoritários e minoritários é ainda } \\
\text { maior quando no caso em que os } \\
\text { direitos de controle são superiores } \\
\text { aos direitos do fluxo de caixa. Sendo } \\
\text { comum acontecer quando há desvio de } \\
\text { regra (uma ação, um voto) e também } \\
\text { em estruturas piramidais }\end{array}$ \\
\hline $\begin{array}{l}\mathrm{AC}-\text { Acordo de } \\
\text { controle }\end{array}$ & $\begin{array}{l}\text { Dummy - } 1 \text { caso os acionis- } \\
\text { tas majoritários possuam AC } \\
\text { e } 0 \text { caso contrário }\end{array}$ & $\begin{array}{l}\text { Carvalhosa (2003); } \\
\text { Baía e Martelenc } \\
(2010),\end{array}$ & + & $\begin{array}{l}\text { Quando os acionistas se unem para } \\
\text { compor a maioria absoluta das ações } \\
\text { votantes, a probabilidade de expro- } \\
\text { priação pode aumentar }\end{array}$ \\
\hline AV - Acordo de Voto & $\begin{array}{l}\text { Dummy - } 1 \text { caso os acionis- } \\
\text { tas minoritários possuam AV } \\
\text { e } 0 \text { caso contrário }\end{array}$ & $\begin{array}{l}\text { Carvalhosa (2003); } \\
\text { Baía e Martelenc } \\
\text { (2010), Carvalhal- } \\
\text {-da-Silva (2012) }\end{array}$ & - & $\begin{array}{l}\text { Quando os minoritários se unem para } \\
\text { compor uma quantidade mínima de } \\
\text { voto com o intuito de aumentar sua } \\
\text { proteção }\end{array}$ \\
\hline Auditoria - Big Four & $\begin{array}{l}\text { Dummy - 1: caso a empresa } \\
\text { seja auditada por uma Big } \\
\text { Four; } 0: C^{* *}\end{array}$ & $\begin{array}{l}\text { Depoers }(2000) ; \\
\text { Berk e Demarzo } \\
\text { (2009; Sonza e } \\
\text { Machado (2018) }\end{array}$ & - & $\begin{array}{l}\text { As empresas que são auditadas por uma } \\
\text { Big Four tornam as informações passa- } \\
\text { das ao conselho bem como as passadas } \\
\text { aos acionistas mais precisa diminuindo } \\
\text { assimetrias informacionais. }\end{array}$ \\
\hline Variável dependente & Descrição/Cálculo & Autores & Sinal & Descrição \\
\hline Q de Tobin & $Q=\frac{(\mathrm{MVE}+\mathrm{B}+\mathrm{D})}{\text { Ativo Total }}$ & $\begin{array}{l}\text { Tobin (1969); } \\
\text { Adaptação feita } \\
\text { por Chung e Pruitt } \\
\text { (1994); Boubakri e } \\
\text { Cosset (1998) }\end{array}$ & & $\begin{array}{l}\text { O Q de Tobin representa um índice de } \\
\text { rentabilidade de mercado que identifi- } \\
\text { ca a situação financeira da empresa }\end{array}$ \\
\hline $\begin{array}{l}\text { Variáveis Indepen- } \\
\text { dentes }\end{array}$ & Descrição/Cálculo & Autores & Sinal $^{2}$ & Descrição \\
\hline $\begin{array}{l}\text { Fator de Expropria- } \\
\text { ção }\end{array}$ & $\begin{array}{l}\text { Gerado por meio da análise } \\
\text { de componentes principais } \\
\text { e fatorial }\end{array}$ & & - & $\begin{array}{l}\text { Quanto maior a expropriação de acio- } \\
\text { nistas minoritários menor o desempe- } \\
\text { nho financeiro }\end{array}$ \\
\hline $\begin{array}{l}\text { Variáveis de Con- } \\
\text { trole }\end{array}$ & Descrição/Cálculo & Autores & Sinal & Descrição \\
\hline
\end{tabular}

2 O respectivo sinal apresentado refere-se a relação da variável com a variável dependente - Q de Tobin. 


\begin{tabular}{|c|c|c|c|c|}
\hline $\mathrm{AL}$ - Alavancagem & $A=\frac{\text { Passivo total }}{\text { Patrimônio Líquido }}$ & $\begin{array}{l}\text { Boubakri e Cosset } \\
\text { (1998) }\end{array}$ & - & $\begin{array}{l}\text { Empresas mais lucrativas geralmen- } \\
\text { te são menos alavancadas, dado a } \\
\text { tendência de que haja diminuição na } \\
\text { alavancagem à medida que aumenta a } \\
\text { eficiência, porque o aumento do endi- } \\
\text { vidamento pode dificultar a alocação } \\
\text { eficiente dos recursos. }\end{array}$ \\
\hline FC - Fluxo de Caixa & & $\begin{array}{l}\text { Opler et al (1999), } \\
\text { Claessens et al } \\
(2002) ;\end{array}$ & - & $\begin{array}{l}\text { Empresas com fluxo de caixa relevante } \\
\text { demandariam maior monitoramento } \\
\text { dos gestores, com a finalidade de } \\
\text { garantir a correta utilização dos } \\
\text { recursos na busca pelo crescimento } \\
\text { das empresas. }\end{array}$ \\
\hline \multirow[t]{2}{*}{$\begin{array}{l}\text { Tam. - Tamanho } \\
\text { AT: Ativo Total } \\
\text { RL: Receita líquida } \\
\text { PL: Patrimônio Lí- } \\
\text { quido }\end{array}$} & \multirow[t]{2}{*}{$\begin{array}{l}\mathbb{T}=\log (\text { Ativo Total }) \\
R=\log (\text { Receita Líquida }) \\
D=\log (\text { Patrimônio Líquid }\end{array}$} & $\begin{array}{l}\text { Macedo e Corrar } \\
(2012)\end{array}$ & + & $\begin{array}{l}\text { Para buscar oportunidades de cres- } \\
\text { cimento, também precisam adotar } \\
\text { políticas de governança mais eficazes, } \\
\text { buscando também a eficiência }\end{array}$ \\
\hline & & $\begin{array}{l}\text { Klapper e Love } \\
(2004)\end{array}$ & - & $\begin{array}{l}\text { Geralmente as maiores empresas têm } \\
\text { mais problemas de agência (devido à } \\
\text { maior dificuldade de monitoramento), } \\
\text { exigindo a busca de mecanismos de } \\
\text { governança mais eficazes. }\end{array}$ \\
\hline
\end{tabular}

Fonte: Elaborado pelos autores ${ }^{a}$ MVE é o preço das ações da firma multiplicado pelo número de ações ordinárias que estão em circulação, PS é o valor de liquidação das ações preferenciais que estão em circulação, e D é a dívida total (Passivo Circulante menos o ativo circulante mais os estoques e a dívida a longo prazo).

onde, $Q$ representa o desempenho de mercado, $\beta$ representa o intercepto e os coeficientes angulares, FE representa o Fator Expropriação, CONT são as variáveis de controle, representam os efeitos fixos da indústria bem como o representa os efeitos fixos do tempo. Por fim, é o termo de erro idiossincrático. O Quadro 1 é formulado visando uma descrição mais detalhada do estudo.

\section{ANÁLISE E DISCUSSÃo dOS RESULTADOS}

A seguinte seção é dividida em três partes, como segue: (i) Fatores compositores da expropriação; (ii) Estatística Descritiva e Correlação; e, (iii) Influência do fator de expropriação sobre o desempenho de mercado

\subsection{Fatores compositores da expropriação}

Inicialmente estimou-se a análise fatorial para todas as variáveis apresentadas como candidatas a caracterização do efeito expropriatório sobre os acionistas minoritários. Nesse sentido verificou-se que seis fatores poderiam ser estimados e usados como explicativos do modelo econométrico estimado pelo GMM. A presente análise se mostrou viável, pois o teste de Bartlett's Test of Sphericity (Bartlett), verificou-se que é improvável a matriz de correlação ser uma identidade, dado a rejeição $(0,00)$ da hipótese nula de não aplicabilidade desta análise. Porém, ao estimar o Kaiser-Meyer-Olkin (KMO) identificou-se um baixo 
ajustamento a este modelo $(0,465)$, sendo necessário uma reestimação incluindo somente as variáveis que apresentaram maior capacidade representativa do fenômeno de expropriação.

Assim, ao reestimar verificou-se que algumas variáveis passaram a ter cargas fatoriais muito baixas sendo estas também retiradas. Com uma nova tabela formada pelas variáveis restantes, foi realizada novamente a análise fatorial e verificação de suas respectivas cargas. Foi aplicada a análise fatorial ao modelo possibilitando a extração de dois fatores, que juntos são capazes de explicar 94,18\% da variância total do modelo (Tabela 1). Para este o teste de Bartlett $(0,00)$ também converge para a aplicação da análise fatorial e, ainda, há uma melhora significativa na consistência dos dados, identificado pelo teste de KMO, apresentando um índice igual a 0,6364. Ainda, por meio do Alpha de Crombach, verifica-se uma consistência interna por meio da intercorrelação entre as variáveis de 94,06\%.

São apresentados na Tabela 1, os eingenvalues, a variância total e as cargas fatoriais para cada variável. Pode-se perceber que a análise sinaliza dois fatores sendo o fator 1 extremamente explicativo em termos de variância dos dados, somente ele explica quase 80\%. As variáveis compositoras deste fator, isto é, que apresentam maior carga fatorial, são as variáveis que representam a estrutura de controle e a estrutura de propriedade do principal acionista, dos três e também dos cinco principais acionistas.

Já o fator 2 apresenta uma capacidade explicativa de 17,05 sobre a variância total dos dados, sendo um fator único, isto é, formado por apenas uma variável que é o desvio acionário do acionista principal.

Tabela 1- Fator de Expropriação

\begin{tabular}{|c|c|c|c|}
\hline \multicolumn{4}{|c|}{ Análise Fatorial } \\
\hline Fator & Eigenvalue & \% da variância & $\%$ acumulada \\
\hline 1 & 5,35 & 0,7713 & 0,7713 \\
\hline \multirow[t]{2}{*}{2} & 1,18 & 0,1705 & 0,9418 \\
\hline & & & Prob $>$ chi $2=0,000$ \\
\hline Fator 1 & Carga Fatorial & Fator 2 & Carga Fatorial \\
\hline APC & 0,9257 & APC & 0,1161 \\
\hline APT & 0,9072 & APT & $-0,2832$ \\
\hline TPAC & 0,9546 & TPAC & 0,2087 \\
\hline TPAT & 0,9744 & TPAT & $-0,1340$ \\
\hline CPAC & 0,9396 & CPAC & 0,2141 \\
\hline CPAT & 0,9651 & CPAT & $-0,0931$ \\
\hline DESA & $-0,03$ & DESA & 0,9870 \\
\hline KMO & 0,6364 & & \\
\hline Alpha-Crombach & 0,9406 & & \\
\hline
\end{tabular}

Fonte: Resultados da pesquisa 
Após ter gerado os fatores percebe-se uma redução significativa na quantidade de variáveis utilizadas para sua composição, sendo esta justificada pela baixa comunalidade entre as elas.

Assim, conforme a literatura apresentada no início deste estudo, diversas variáveis como o pagamento de dividendos, a emissão de ADRs, a auditoria feita por uma das quatro maiores empresas, acordo de acionistas e também cláusulas contratuais como possíveis candidatos a explicação do fenômeno de expropriação. Porém, econometricamente não apresentam comunalidades para serem agrupados como comentado acima. Os autores acreditam que isto se deve devido à natureza heterogênea das variáveis, isto é, mesmo havendo influências individuais e capacidade de explicação sobre o referido fenômeno, estas, coletivamente, não conseguem explicar tal fenômeno.

Assim, as variáveis que representam o controle/propriedade acionária bem como o desvio entre elas são as variáveis explicativas e geradoras dos fatores deste estudo. Depois de gerado os fatores estimou um o GMM e verificou-se que o fator um explica o desempenho negativa e significativamente, porém o fator dois não. Nesse sentido, os autores optaram por retirar do modelo o fator dois, reestimando a análise fatorial com apenas um fator para identificar se há mudança no ajustamento do modelo (KMO) bem como na consistência interna (Alpha de Crombach). Nesse sentido, o KMO continua com o mesmo ajustamento e o Alpha de Krombach apresenta uma melhora alcançando 97,25\%. Portanto, os autores optaram em manter apenas o fator um justificado por ser estatisticamente significativo e também por apresentar uma melhora na consistência interna.

Por fim, verificou-se a consistência do modelo por meio da matriz de resíduos e também por meio da matriz anti-imagem. Por fim, a rotação dos dados pelo método Varimax e Oblimin verificou-se que a interpretação dos dados não se altera substancialmente.

\subsection{Estatística Descritiva e Correlação}

Conforme identificado nos procedimentos metodológicos, antes de iniciar a análise, são aplicados o teste de correlação e a verificação da consistência dos dados através da estatística descritiva.

No geral, como esperado, é identificada uma correlação forte (igual ou acima de 0,7) entre as variáveis que mensuram a estrutura acionária das empresas brasileiras sendo elas: estrutura de controle/propriedade do acionista majoritário, dos três principais acionistas e também dos cinco principais acionistas; dos desvios acionários dado a estrutura acionária do acionista majoritário, dos três e dos cinco principais acionistas; entre o valor de mercado das empresas a proxy do Q de Tobin, entre patrimônio líquido, ativo total, receitas operacionais e lucro líquido, por fim verificou-se também uma alta correlação entre o lucro líquido e os dividendos pagos. Nesse sentido, para evitar possíveis problemas de colinearidade, nenhuma dessas variáveis com alta correlação é utilizada na mesma regressão.

Em relação as demais variáveis, principalmente no tocante as relacionadas a expropriação, estas não apresentaram correlação elevada podendo incorrer em uma não comunalidade como vista na análise fatorial, isto é, conforme a literatura há a influência destas sobre o fenômeno da expropriação, porém econometricamente não se pode formar um fator em comum. 
Tabela 2 - Estatística Descritiva

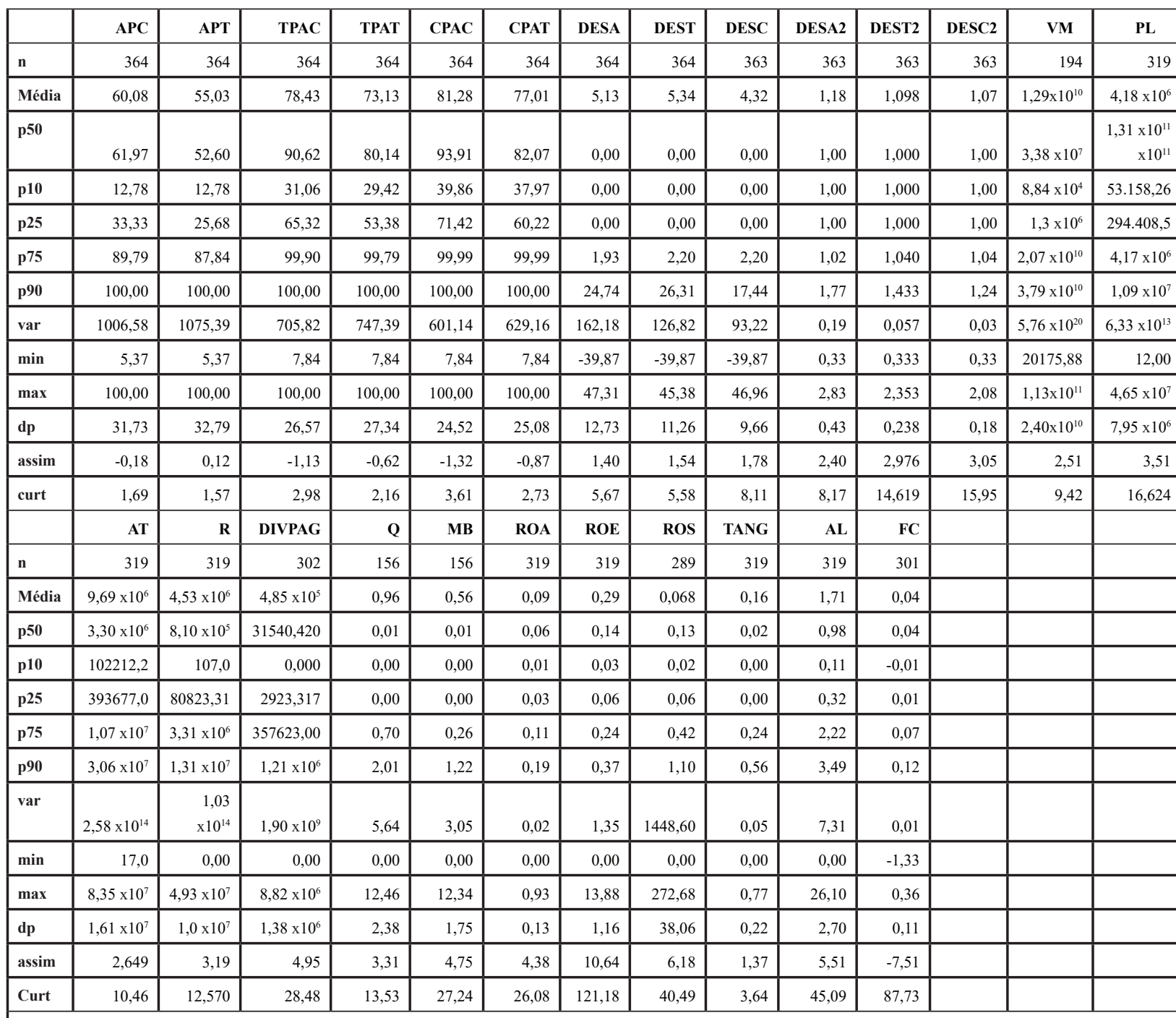

Fonte: Resultados da pesquisa

Legenda: : APC $($ APT) = estrutura de controle (propriedade) do acionista principal, APT (TPAT) = estrutura de controle (propriedade) dos três principais acionistas; CPAC $(\mathrm{CPAT})=$ estrutura de controle (propriedade) dos cinco principais acionistas; DESA e DESA2 = desvio acionário do acionista principal, DEST e DEST2 = Desvio acionário dos três principais acionistas; DESC e DESC2 = Desvio acionários dos cinco principais acionistas; $\mathrm{VM}=$ valor de mercado; $\mathrm{PL}=\mathrm{Patrimônio} \mathrm{Líquido;} \mathrm{AT}=$ ativo total; $\mathrm{R}=$ receitas operacionais; DIVPAG = dividendos pagos; $\mathrm{FC}=$ Fluxo de caixa; $\mathrm{Q}=\mathrm{Q}$ de Tobin; $\mathrm{MB}=$ Market-to-book; ROA= retorno sobre o ativo; ROE = retorno sobre o patrimônio; ROS = margem operacional; $\mathrm{TANG}=$ tangibilidade $\mathrm{AL}=$ alavancagem; $\mathrm{n}=$ número de observações, var. $=$ Variância; min. $=$ mínimo; max. $=$ máximo; $\mathrm{dp}=\mathrm{Desvio}$ padrão; assim = assimetria; Curt. = curtose $\mathrm{Q}=\mathrm{Q}$ de Tobin; $\mathrm{AL}=$ alavancagem; $\mathrm{AT}=$ Ativo total $\mathrm{PL}=$ Patrimônio Líquido; $\mathrm{n}=$ número de observações, var. $=$ Variância; min. $=$ mínimo; max. = máximo; assim = assimetria; Curt. = curtose 
Como supracitado, após verificação das correlações, foram estimadas as estatísticas descritivas com o intuito de demonstrar a consistência dos dados e também apresentar algumas medidas importantes para o estudo. Conforme tabela 1 a seguir são evidenciadas as estatísticas descritivas das empresas brasileiras negociadas na B3.

Como verificado na Tabela 1 , depois da aplicação da winsorização de 1\%, as variáveis apresentam médias e medianas muito próximas, com exceção das variáveis de tamanho (PL, AT e R), as quais foram necessárias transformações, aplicando logaritmo neperiano.

Como evidenciado na estatística descritiva é evidenciado que a média da estrutura de controle tanto do acionista principal quanto dos três e dos cinco principais acionistas é extremamente concentrada totalizando $60,08 \%, 78,43 \%$ e $81,28 \%$ respectivamente. Esta demonstra um controle extremamente concentrado nas mãos de poucos acionistas aumentando as chances de expropriação por parte de acionistas minoritários.

Adicionalmente, a estrutura de propriedade tanto do acionista principal quanto dos três e dos cinco principais se mostra concentrado também, porém com valores médios inferiores aos evidenciados para a estrutura de controle. Em média a estrutura de propriedade do acionista principal totaliza 55,03\%; dos três principais totaliza 80,14\%; e, dos cinco principais acionistas totaliza 77,01\%. Esses dados comprovam que há a fuga da regra 'uma ação um voto', isto é, há um desvio acionário identificado pela diferença entre estrutura de controle e estrutura de propriedade sendo este percentual considerável tanto em termos absolutos quanto em termos relativos.

Em termos relativos, identificou-se um desvio médio de 5,13\% para o acionista principal (DESA), não se alterando significativamente se considerado os três - 5,34\% - ou para os cinco acionistas principais - 4,32\%. Isto demonstra que essencialmente o desvio acionário tem sua origem na detenção acionária do principal acionista. Já em termos absolutos verifica-se um desvio de 0,18 para o principal acionista (DESA2) sendo decrescente para os três $(0,098)$ e para os cinco acionistas $(0,07)$.

As demais variáveis apresentadas que merecem destaque são as variáveis de desempenho, - ROA, ROE, ROS, Q - de tamanho - AT, PL, R - e de estrutura de capital. Em relação as variáveis de desempenho verificam-se que o retorno sobre os ativos das empresas totalizam 9\%, isto é, cada um $\mathrm{R} \$ 100,00$ de bens e direitos que a empresa possui há um retorno de $\mathrm{R} \$ 9,00$. Da mesma forma e com uma magnitude maior, o retorno sobre o patrimônio líquido alcança 29,00, apontando que para cada $\mathrm{R} \$ 100,00$ de capital próprio integralizados pelos proprietários há um retorno médio de $\mathrm{R} \$ 29,00$. Ainda, em termos de desempenho contábil, a margem operacional líquida sinaliza um retorno médio de $6,68 \%$, demonstrando que para cada $\mathrm{R} \$ 100,00$ de receitas de vendas $\mathrm{R} \$ 6,68$ são sobras líquidas de custos, despesas financeiras e também impostos.

Alternativamente as estas variáveis de desempenho contábil, mensurou-se o valor médio do desempenho por uma proxy de valor de mercado (variável usada no modelo a seguir) que relaciona o valor de mercado da empresa com seu respectivo valor patrimonial. Pelas estatísticas da tabela 1 verifica-se que em média o valor de mercado não supera o valor contábil dos ativos totais, pois o Q de Tobin é de 0,96, não superando a unidade. 
Em relação as variáveis de tamanho, identificou-se que em média o ativo total alcança valores expressivos de $\mathrm{R} \$ 969.000 .000$, já em relação ao patrimônio líquido os valores também são altos totalizando $\mathrm{R} \$ 418.000 .000,00 \mathrm{e}$, por fim, as receitas operacionais da empresa alcançam um valor médio de $\mathrm{R} \$ 453.000 .000,00$.

Em termos de estrutura de capital, evidenciou-se que as empresas da amostra dão preferência pela utilização de capital de terceiros comparativamente a capital próprio, isto é, se integralizado $\mathrm{R} \$ 100,00$ no capital social da empresa em contrapartida são captados $\mathrm{R} \$ 176,00$ de empréstimos e financiamentos.

\subsection{Influência do fator de expropriação sobre o desempenho de mercado}

Como apontado nos procedimentos metodológicos, para identificar a influência da expropriação de acionistas minoritários sobre o valor de mercado das empresas brasileiras negociadas na B3 é aplicado o método de dados em painel balanceado por GMM-Sys. A validade dos resultados expostos na tabela 3 a seguir, dependem da adequação dos modelos aos pressupostos do referido método, sendo que tais pressupostos são representados pelos testes evidenciados na parte inferior desta Tabela 3. Inicialmente, o teste de Arellano e Bond (1991) (Ar 1 e Ar 2) indicou que tanto o modelo não rejeita a hipótese nula de ausência de correlação serial nos resíduos de primeira limitando a aplicação do modelo GMM-Sys dinâmico, mas não comprometendo as análises. No teste de Hansen (1982), a presente análise não rejeita a hipótese nula a um nível de significância de $1 \%$, evidenciando que não existem, a princípio, problemas de especificação nas variáveis instrumentais. Os instrumentos utilizados são as próprias variáveis defasadas, como sugerido por Almeida et al. (2010). No teste qui-quadrado $\left(\chi^{2}\right)$ há a rejeição da hipótese nula, indicando que existe associação entre os grupos de variáveis. O teste tipo Fisher (1932) identificou que não há raiz unitária em nenhum um dos painéis utilizados rejeitando a hipótese nula de presença de raiz unitária, sendo esta confirmada tanto pela inversa $\chi^{2}$, quanto pela Inversa normal (), inversa logit () e inversa normal modificada (). Por fim, o teste de Westerlund (2007) rejeita a não rejeita a hipótese nula de não cointegração das séries.

Na parte superior da tabela 3, é evidenciada a estimação da influência do fenômeno de expropriação sobre o desempenho de mercado. De uma maneira geral, a expropriação é negativamente relacionada com o desempenho de mercado mensurado pelo $\mathrm{Q}$ de Tobin, isto é, há uma relação inversa entre o fenômeno de expropriação de acionistas minoritários e o desempenho da empresa. Assim, um aumento em $100 \%$ na expropriação de acionistas o desempenho de mercado é deteriorado em médio 3,27\%, sendo esta relação estatisticamente significativa a $1 \%$. 
Tabela 3 - Influência do fator de expropriação sobre o desempenho de mercado

\begin{tabular}{|c|c|c|c|c|c|c|}
\hline Variável & Coef. & Erro Padrão & $\mathbf{z}$ & p-valor & \multicolumn{2}{|c|}{ Intervalo de Confiança } \\
\hline \multicolumn{7}{|l|}{$\begin{array}{l}\text { Q de } \\
\text { Tobin }\end{array}$} \\
\hline L1. & $-2,1216$ & 0,0197 & $-10,77$ & $0,00 * * *$ & $-2,500$ & $-1,7300$ \\
\hline Exprop. & $-0,00032$ & 0,00011 & $-2,75$ & $0,00 * * *$ & $-0,00055$ & $-0,00009$ \\
\hline $\mathbf{A L}$ & $-0,0007$ & 0,00026 & $-2,9$ & $0,00 * * *$ & $-0,0013$ & $-0,00025$ \\
\hline $\ln P L$ & $-0,00229$ & 0,0006 & -328 & $0,00 * * *$ & $-0,003$ & $-0,0009$ \\
\hline FC & 0,00048 & 0,0007 & 0,68 & 0,495 & $-0,0009$ & 0,0018 \\
\hline const & 0,0395 & 0,011 & 3,39 & $0,00 * * *$ & 0,0166 & 0,0624 \\
\hline \multicolumn{7}{|c|}{ Testes } \\
\hline $\mathbf{N}$ & chi2 & chi2p & hansen & hansenp & ar1 & $\operatorname{ar} 1 p$ \\
\hline 109 & $\begin{array}{r}1,56 \\
\times 10^{9}\end{array}$ & 0,000 & 254,51 & 1,4 & $-0,2833$ & 0,7769 \\
\hline & & & & & ar2 & $\operatorname{ar2p}$ \\
\hline & & & & & $-0,3832$ & 0,7016 \\
\hline
\end{tabular}

\section{Fonte: Resultados da pesquisa}

Legenda: Variável dependente: Q de Tobin; L1. = variável dinâmica (variável dependente defasada em um período; Exprop. $=$ fator de expropriação; $\mathrm{FC}=$ fluxo de caixa; $\mathrm{AL}=$ alavancagem; $\ln (\mathrm{Pl})=$ logaritmo natural do patrimônio Líquido; const.: constante; $\mathrm{N}=$ número de observações chi2 = teste qui-quadrado; Hansen = teste de Hansen; Ar1 e Ar2 = correlação serial de primeira e segunda ordem; * Significância a 10\%; ** Significância a 5\%; *** Significância a 1\%.

Como verificado na composição do fator de expropriação, esta se dá principalmente pela estrutura de controle e também de propriedade das firmas. Este achado está de acordo com os apontamentos de Silveira (2004) e Sonza e Kloeckner (2014), no qual, identificam que no Brasil, os acionistas detentores do controle tendem a utilizá-lo em prol dos seus interesses pessoais, indo contra às expectativas dos minoritários. Conforme aponta La Porta et al. (1998) o controle direto de acionistas majoritários é uma resposta a ausência da proteção legal aos direitos dos investidores, porém impactando numa maior probabilidade de expropriação (LANZANAa, 2004) o que leva a menores níveis de desempenho.

Em termos de variáveis de controle verificou-se que a alavancagem influencia negativamente o desempenho de mercado sendo estatisticamente significativa a $1 \%$. Este achado está de acordo com Boubakri e Cosset (1998), no qual apontam que existe uma tendência de que haja diminuição na alavancagem à medida que aumenta o desempenho, porque o aumento do endividamento pode dificultar a alocação eficiente dos recursos, seguindo a lógica de que empresas mais lucrativas geralmente são menos alavancadas. 
A variável relativa ao tamanho (patrimônio líquido), mostrou-se negativamente relacionada com a eficiência, sendo estatisticamente significativa a 1\% também. Esse resultado vai ao encontro com os apontamentos de Klapper e Love (2004), os quais afirmam que o efeito do tamanho sobre a governança pode ser negativo, pois geralmente nas maiores empresas ocorrem mais problemas de agência (devido à maior dificuldade de monitoramento), exigindo a busca de mecanismos de governança mais eficazes.

Por fim em termos de fluxo de caixa, este influencia positivamente o desempenho das empresas, porém não é estatisticamente significativo para explicar o desempenho de mercado. Ainda, verificou-se que a variável dependente defasada um período é estatisticamente significativa para explicar o desempenho de mercado no momento $t$.

\section{Considerações finais}

O presente artigo buscou compor um fator constituído por variáveis que caracterizam a expropriação de minoritários para posterior identificação da influência da expropriação de acionistas minoritários sobre o desempenho de mercado das empresas brasileiras de capital aberto negociadas no Brasil, Bolsa e Balcão (B3).

Para a efetivação do presente estudo constituiu-se uma amostra com oitenta empresas brasileiras de capital aberto com ações ordinárias e preferenciais negociadas a B3, sendo as informações coletadas de 2010 à 2018. Nesses dados fez-se, inicialmente, uma análise estatística descritiva e análise de correlação, após, foi construído um fator representativo da expropriação de acionistas minoritários por meio da Análise Fatorial (AF) estimado por meio de Componentes Principais (ACP). Posteriormente, foram aplicados modelos de painéis dinâmicos, estimados pelo Método dos Momentos Generalizados (GMM) para verificar a referida influência.

$\mathrm{Na}$ análise de resultados foi identificado que o fator expropriação influencia negativamente o desempenho de mercado das empresas sendo esta relação estatisticamente significativa. Esta relação representa o argumento teórico de que um acúmulo de ações por um controlador/proprietário, ou mesmo por um número reduzido de controladores/proprietários (três ou cinco) pode influenciar o desempenho das empresas, sendo estas as variáveis representativas da participação acionária capazes de retratar o fenômeno de expropriação.

Como apontado na introdução deste estudo, a concentração acionária traria benefícios para as organizações, visto que aumentaria a eficácia do monitoramento aos executivos, contudo, esta constatação se refere somente quando a proteção ao investidor é eficaz, visto principalmente em países anglo-saxões e com base em commom law (JENSEN; MECKING, 1976, LA PORTA et al., 1998, 1999). Assim, na ausência de regulamentações adequadas que protegem os minoritários, o efeito alinhamento pode tornar-se contraditório aumentando a probabilidade de expropriação, levando o conflito de agência, entre acionistas majoritários e minoritários, a tomarem maiores proporções (BERK; DEMARZO, 2009; ROSSETTI; ANDRADE, 2013).

O artigo em questão apresenta contribuições teóricas e empíricas. Em termos teóricos o presente trabalho avança em abordar diversos candidatos a expropriação de acionistas mi- 
noritários revisando-os e especificando sua relação com a expropriação. Verificou-se na literatura que aspectos como o pagamento de dividendos, aspectos jurídicos (acordo de controle/ voto, tag along, drag along), aspectos acionários (estrutura de propriedade/controle e desvio acionário), aspectos de auditoria e também de desenvolvimento de mercado de capitais (novo mercado, nível 1 e 2) são apontados como indutores/inibidores do fenômeno de expropriação.

Nesse sentido, a proposta satisfaz a problemática levantada de identificação das variáveis caracterizadoras do fenômeno de expropriação. Ainda, o presente estudo valida e reforça que as variáveis representativas da propriedade bem como de controle são as proxies mais adequadas para representar o fenômeno de expropriação.

Em termos empíricos, a identificação da influência do fenômeno de expropriação sobre o desempenho se mostra alinhada com a literatura, porém o presente estudo condensa as variáveis relativas a participação acionária formando um fator, dando mais robustez se comparada aos trabalhos anteriores. Portanto, econometricamente, as variáveis de propriedade e de controle são as que se mostraram mais eficazes na representação do referido fenômeno. Estes achados demonstram que não há nenhuma emissão substancial de variável para a caracterização do fenômeno de expropriação.

Algumas limitações a serem consideradas foram referentes à dificuldade de obter estudos realizados no Brasil que relacionem a expropriação amplamente. Outra limitação é a amostra, no qual apresenta painéis moderados podendo não representar assintoticamente a realidade das empresas negociadas na B3. Uma sugestão para pesquisas futuras seria a ampliação desse estudo, dividindo-o em setores.

\section{REFERÊNCIAS}

ALVES, S. M. Internacionalização de Empresas e o Fechamento do Capital: Um Estudo sobre a Deslistagem no Mercado Brasileiro. Uberlândia 2016. Dissertação de Mestrado (Mestrado em Adminsitração), Universidade Federal de Uberlândia, Uberlândia, MG, Brasil, 2016.

ARELLANO, M.; BOND, S. Some tests of specification for panel data: Monte Carlo evidence and an application to employment equations. Review of Economic Studies, 58, n. 2, p. 277-297, 1991.

ARELLANO, M.; BOVER, O. Another look at the instrumental variable estimation of error-components models. Journal of Econometrics, v. 68, n.1, p. 29-51, 1995.

ATHARI, S. A.; ADAOGLU, C.; BEKTAS, E. (2016). Investor protection and dividend policy: The case os Islamic and conventional banks. Emergin Markest Review, v. 27, n. C, p. 100-117.

BAÍA, E.; MARTELANC, R. Expropriação e Governança Corporativa: Definição do potencial de expropriação dos acionistas controladores e correlação com os mecanismos de Governança Corporativa. Dissertação (Mestrado em Administração) - Universidade de São Paulo, São Paulo, 2010.

BARROS, L. A. B. C. et al. Endogeneity in Corporate Finance Empirical Research. In: Social Science Research Network. 2009.

BERK, J.; DEMARZO, P. Finanças empresariais. Porto Alegre: Bookman, 2006.

BERLE, A., JR.; MEANS, G. The modern corporation and private property. Chicago: Commerce Clearing House, 1932. 
BLUNDELL, R.; BOND, S. Initial conditions and moment restrictions in dynamic panel data models. Journal of Econometrics, v. 87, n. 1, p. 115-143, 1998.

BOND, S. Dynamic panel data models: A guide to micro data methods and practice. Portuguese Economic Journal, v. 1, n. 2, p. 141-162, 2002.

BOUBAKRI, N.; COSSET, J. C. The financial and operating performance of newly privatized firms: evidence from developing countries. Journal of Finance, v. 53, n. 3, p. 1081-1110, 1998.

CARVALHAL-DA-SILVA, A. Do shareholder agreements affect market valuation? Evidence from Brazilian listed firms. Journal of Corporate Finance, v. 18, n. 4, p. 919-933, 2012.

CARVAlhosA, M. Comentários à Lei de Sociedades Anônimas. Vol. 2. $3^{\mathrm{a}}$ Ed. Revisada e Atualizada. São Paulo: Ed. Saraiva, 2003.

CHUNG, K.; PRUITT, S. A simple approximation of Tobin's Q. Financial Management, v. 23, n. 3, p. 70-74, 1994.

CLAESSENS, S.; DJANKOV, S.; FAN, J. P. H.; LANG, L. H. P. Disentangling the incentive and entrenchment effects of large shareholdings. The Journal of Finance, v. 57, n. 6, p. 2741-2771, 2002 .

CORREIA, L. F.; AMARAL, H. F.; LOUVET P. Um índice de avaliação da qualidade da governança corporativa no Brasil. Revista de Contabilidade e Finanças, v. 22, n. 55, p. 45-63, 2011.

DA SILVA, A. L. P.; BUENO, G.; L.; KOETZ, C. M.; MARCON, R. Uns Mais Iguais que Outros: a Relação entre Concentração de Propriedade e os Acordos de Acionistas. Contabilidade, Gestão e Governança, v. 18, n. 3, p. 85-104, 2015.

DEPOERS, F. A cost benefit study of voluntary disclosure: Some empirical evidence from French listed companies. European Accounting Review, v. 9, n. 2, p. 245-263, 2000.

EHRHARDT, O.; NOWAK, E. Private benefits and minority shareholders expropriation. Empirical evidence from IPOs of German family-owned firms. Frnakfurt: Center for financial studies, 2001/10, 2001.

FACCIO, M.; LANG, L. H. P. The ultimate ownership of Western European Corporation. Journal of Financial Economics, v. 65, n. 3, p. 365-395, 2001.

FISHER, R. A. Statistical methods for research workers. 4th edition. Edinburgh: Oliver e Boyd, 1932.

GELMAN, M.; DE CASTRO, L. R. K.; SEIDLER V. Efeitos da vinculação de conselheiros ao acordo de acionistas no valor da firma. Revista de Administração de Empesas, v. 55, n. 3, p. 345 $358,2015$.

HANSEN, L. P. Large sample properties of generalized method of moments estimators. Econometrica, v. 50, n. 4, p. 1029-1054, 1982.

JENSEN, M. C.; MECKLING, W. Theory of the firm: managerial behavior, agency costs and ownership structure. Journal of Financial Economics, v. 3, n. 4, p. 305-360, 1976.

KLAPPER, L. F.; LOVE, I. Corporate governance, investor protection, and performance in emerging markets. Journal of Corporate Finance, v. 10, n. 5, p. 703-728, 2004.

LA PORTA, R.; LOPEZ-DE-SILANES, F.; SHLEIFER, A.; VISHNY, R. Law and finance. Journal of Political Economy, v. 106, n. 6, p. 1113-1155, 1998.

LA PORTA, R.; LOPEZ-DE-SILANES, F.; SHLEIFER, A. Corporate ownership around the world. The Journal of Finance, v. 54, n. 2, p. 471-517, 1999. 
Agency problems and dividend policies around the world. The Journal of Finance, v. 55, n. 1, p. 1-33, 2000.

LACAVE, I. S.; GUTIÉRREZ, N. B. Specific Investments, Opportunism and Corporate Contracts: A Theory of Tag-along and Drag-along Clauses. European Business Organization Law Review, v. 11, n. 3 , p. $423-458,2010$.

LAMEIRA, V. J.; NESS, W. L., Jr. Os determinantes da qualidade da governança praticada pelas companhias abertas brasileiras. Revista de Negócios, v. 16, n. 3, p. 33-52, 2011.

LANZANA, A. P. Relação entre disclosure e governança corporativa das empresas brasileiras. Dissertação (Mestrado em Administração) - Programa de Pós-Graduação em Administração, Faculdade de Economia, Administração e Contabilidade da Universidade de são Paulo, 2004.

LUO, Q.; LI, H.; ZHANG, B. Financial Constrainsts and the cost of equity: Evidence of moral hazard of the controlling shareholder. Internacional Review of Economics and Finance, v.36, $\mathrm{n}$. s/n, p. 99-106, 2015.

MACEDO, M. A. D. S.; CORRAR, L. J. Análise comparativa do desempenho contábil-financeiro de empresas com boas práticas de governança corporativa no Brasil. Revista Contabilidade e Controladoria, v. 4, n. 1, p. 42-61, 2012.

MARCIANO, L.M. S. A Lei Sarbanes - Oxley e seus efeitos em Empresas Brasileiras. Limeira - São Paulo, 2015.

MÁTYÁS, L. Generalized Method of Moments Estimation. Cambridge University Press, 316 p., 1999.

MINGOTI, S. A. Análise de dados através de métodos de estatística multivariada: uma abordagem aplicada. Belo Horizonte: Editora UFMG, 2005.

Análise de dados através de métodos de estatística multivariada: uma abordagem aplicada. Belo Horizonte: Editora UFMG, 2017.

MORCK, R.; SHLEIFER, A.; VISHNY, R. W. Management ownership and market valuation: an empirical analysis. Journal of Financial Economics, v. 20, n. 1, p. 293-315, 1998.

OPLER, T., LEE P.; RENE, S.; WILLIAMSON, R. The determinants and implications of corporate cash holdings, Journal of Financial Economics, v. 52, n. 1, p. 3-46, 1999.

PUNSUVO, F. R.; KAYO; K.; BARROS, L. A. B. C. O Ativismo dos Fundos de Pensão e a Qualidade da Governança Corporativa. Revista de contabilidade e Finanças, v. 18, n. 45, p. 63-72, 2007.

ROSETTI, J. P.; ANDRADE, A. Governança Corporativa: Fundamentos, Desenvolvimento e Tendências. 7. ed. São Paulo: Atlas, 2014.

ROSSI, F.; BOYLAN R.; CEBULA, R. Financial decisions and ownership structure as control mechanisms of agency problems: evidence from Italy. Corporate Governance: The International Journal of Business in Society, v. 8, n. 3, p. 531-563, 2017.

SHLEIFER, A.; VISHNY, R. W. A Survey of Corporate Governance. Journal of Finance. v. 52, n. 2, 1997.

SILVA, A. L. C.; LEAL, R. P. C. Corporate governance index, fi rm valuation and performance in Brazil. Revista Brasileira de Finanças, v. 3, n. 1, p. 1-18, 2005.

SILVEIRA, A. D. M.; LAZANA, A. P.; BARROS, L. A.; FAMÁ, R. Efeito dos acionistas controladores no valor das companhias abertas brasileiras. Revista de Administração da Universidade de São Paulo, v. 39, n. 4, p. 362-372, 2004. 
SCHMIDT, C.; FAHLENBRACH, R. Do exogenous changes in passive institutional ownership affect corporate governance and firm value?. Journal of Financial Economics, v. 124, n. 2, p. 285 306, 2017.

SONZA. I. B.; KLOECKNER, G. O. Eficiência em estruturas de propriedade concentradas e compensação de executivos: novas evidências para o Brasil. Tese de Doutorado, Universidade Federal do Rio Grande do Sul, Porto Alegre, Rio Grande do Sul, Brasil, 2012.

SONZA, I. B.; KLOEKNER, G. O. Governança em estruturas proprietárias concentradas: novas evidências para o Brasil. Revista de Administração de São Paulo, v. 49, n. 2, p. 322-338, 2014.

SONZA, I. B.; GRANZOTTO, A. Are pension funds good monitors?. RAUSP Management Journal, v. 53, n. 2, p. 190-201, 2018.

SONZA, I. B.; MACHADO, W. N. Do the largest corporations disclose less information because they have more private benefits? In: Encontro Brasileiro de Finanças. Anais Encontro Brasileiro de Finanças. São Paulo, Brasil, 2018.

STULZ, R. M. Globalization of Equity Markets and the Cost of Capital. National Bureau of Economic Research, Working Paper, 1999.

TOBIN, J.A General Equilibrium Approach to Monetary Theory. Journal of Money, Credit and Banking, 1969.

WESTERLUND, J.; EDGERTON, D. Simple Tests for Cointegration in Dependent Panels with Structural Breaks, Oxford Bulletin of Economics and Statistics, v. 70, n. , p. 665-704, 200

WINTOKI, M. B.; LINCK, J. S.; NETTER, J. M. Endogeneity and the dynamics of corporate governance, 2008 .

Submetido em: 10-5-2019

Aceito em: 5-10-2020 